\title{
Knowledge of emergency contraception among students in a tertiary institution in a developing country
}

This article was published in the following Dove Press journal:

Open Access Journal of Contraception

15 May 2012

Number of times this article has been viewed

\author{
Abiodun Adeniyi \\ Adewunmi ${ }^{\prime}$ \\ Kabiru Afolarin Rabiu' \\ Adetokunbo Olufela Tayo' \\ Tawakwalit Abimbola \\ Ottun' \\ Bolu Sunday Adeboye ${ }^{2}$ \\ Raheem Akinwunmi \\ Akindele ${ }^{3}$ \\ 'Department of Obstetrics and \\ Gynaecology, Lagos State University \\ Teaching Hospital, Ikeja-Lagos, \\ ${ }^{2}$ Department of Obstetrics and \\ Gynaecology, State Specialist Hospital \\ Akure Ondo State, ${ }^{3}$ Department Of \\ Physiology, Obafemi Awolowo College \\ Of Health Sciences, Olabisi Onabanjo \\ University Teaching Hospital, Sagamu, \\ Ogun State, Nigeria
}

Background: Emergency contraception (EC) has been available in developing countries without prescription for some time. There is, however, little research into the extent of the knowledge of mode of action, effectiveness, and availability of this form of contraception in rural areas.

Objectives: To assess the knowledge of EC with respect to mode of action, effectiveness, and availability in rural areas among students in a tertiary institution in a developing country.

Methods: A questionnaire was distributed to tertiary students in a university in rural area in a developing country. This questionnaire asked about their knowledge of the mode of action of EC, its availability over the counter, its cost, and the student's willingness to purchase it.

Results: Some 488 of the 500 questionnaires were returned. One hundred and eight $(22.1 \%)$ of the students had used EC or bought it for a girlfriend at some stage in the past. Two hundred and forty four (50.0\%) knew the correct timeframe for its use, while $201(41.2 \%)$ were not aware of its availability over the counter in pharmacies, and $150(30.7 \%)$ felt unable to purchase EC in a pharmacy where they are known. One hundred (20.5\%) of the participants were aware of the cost of EC.

Conclusion: The students had good knowledge of the timeframe for the use of EC, but lacked information regarding the availability and the cost of EC in the community.

Keywords: developing country, emergency contraception, knowledge

\section{Introduction}

Emergency contraception (EC), also known as post-coital contraception or the morning after pill, refers to a group of birth control modalities that, when used within defined time limits after unprotected intercourse, can prevent an unwanted pregnancy. ${ }^{1}$ EC is intended for occasional or emergency use only, and not as a regular contraceptive.

Emergency contraception is usually employed when intercourse is unprotected. Situations that can cause this include failure of barrier methods such as spillage, breakage, or misuse of condom, sexual assaults, failed coitus interruptus, or two or more consecutive missed oral contraceptive pills. ${ }^{2}$

There are various methods of emergency contraception, including hormone contraceptive pills (morning after pills) which were initially described in $1974,{ }^{3}$ intrauterine contraceptive devices (IUCD), and mifepristone. In addition to the above, levonorgestrel (LNG) is used in most developing countries and uliprisal (UPA) is used in Europe and the United States of America. ${ }^{4,5}$ These contraceptives are effective for different lengths of time post coitus, with Yuzpe effective for up to 72 hours, LNG effective for up to 96 hours, and UPA effective for up to 120 hours. ${ }^{4,5}$
Correspondence: Abiodun Adeniyi

Adewunmi

Institute of Fertility Medicine,

Department of Obstetrics and

Gynaecology, Lagos State University

Teaching Hospital, Ikeja-Lagos, Nigeria

Tel+2348023077827

Email niyi_55@yahoo.com 
At the time of this study, the two methods of EC available in Nigeria were copper-T IUCD and the more common LNG in the form of two $750 \mathrm{mg}$ postinor-2 tablets. LNG is available in the family planning clinics of public hospitals, and in private pharmacies as a non-prescription (over the counter, or OTC) drug. ${ }^{6}$ LNG is given free of charge in public hospitals, but is sold for approximately US\$1.03 in private pharmacies.

Every year, unplanned pregnancies lead to at least 50 million abortions worldwide, many of which are unsafe and subsequently result in 80,000 maternal deaths. ${ }^{7}$ The incidence of induced abortion in Nigeria (the most populous country in Africa) is 25 per 1000 women of reproductive age per year. There are approximately 610,000 abortions performed annually in Nigeria, of which $60 \%$ are believed to be unsafe, ${ }^{8}$ and these abortions are responsible for $20 \%$ of maternal deaths in Nigeria, ${ }^{8} 27.4 \%$ to $34.6 \%$ in Cameroon, ${ }^{9}$ and $21 \%$ in Uganda. ${ }^{10}$ Most of these unwanted pregnancies result from a lack of use of modern methods of contraception, including emergency contraception. In Nigeria, the use of modern methods is as low as $9 \%$ and $1.4 \%$ for men according to the 1999 Nigerian demographic and health survey. ${ }^{7}$ Young people, particularly those in tertiary institutions, are particularly vulnerable to unsafe abortions. Widespread availability of EC has the potential to prevent unplanned unwanted pregnancies, and therefore reduce the rate of terminations. ${ }^{11}$

However, in order to avail themselves of EC when needed, women must be aware of its period of effectiveness, accessibility over the counter, and cost. They must be able to obtain EC confidentially and without embarrassment. The latter factors may be particularly relevant among women in rural and remote settings where there may be only one private pharmacy and no government-owned hospital. We therefore undertook this study to ascertain the extent of knowledge of the period of effectiveness, cost, and accessibility of EC among a group of tertiary students in Akungba (a university community in Ondo State, Nigeria). It was expected that these students would be the part of this community that is most likely to be well-informed about contraceptive methods or to have the ability to access such information.

\section{Materials and methods Design and setting}

This study was a descriptive cross-sectional survey at the Adekunle Ajasin University, Akungba-Akoko (a rural community) in Ondo state, Nigeria. Formal approval was granted by the Ethics and Research Committee of the university.

\section{Study population}

Male and female undergraduates in the campus were administered a questionnaire on 10 May, 2011.

\section{Sample size determination}

A recent study reported that the contraceptive prevalence rate in Nigeria was approximately $12 \% .{ }^{12}$ We used this figure to calculate the sample size for this study using the formula $\mathrm{n}=\mathrm{Z}^{2} \mathrm{p}(1-\mathrm{p}) / \mathrm{e}^{2}$ to obtain a sample size of $162,{ }^{13,14}$ and projected a sample size of 500. The sample was expected to be a good representation of the whole population because all of the participants satisfied the minimum requirement for admission to the university.

\section{Data collection}

All participants were given a one-page explanation of the purpose of the study. The instrument for data collection was a pretested self-administered questionnaire. This university did not have a medical school at the time the study was conducted. The questionnaire was designed in conjunction with staff of the university health center where a small pilot study was carried out to ensure that questions were easily understood by participants.

Consecutive consenting students were administered the questionnaire until the desired sample size was reached. Confidentiality was maintained by not collecting the participants' names and addresses. Completed questionnaires were immediately collected into a closed box to ensure anonymity. The questionnaire solicited the participant's age, sex, whether they had ever used or bought LNG tablets for EC, their understanding of the timeframe for its use, availability, and cost, and their confidence to buy EC in a pharmacy where they are known.

\section{Data analysis}

Data were collated and analyzed using simple percentages.

\section{Results}

A total of 488 of 500 questionnaires were returned partially or fully completed, giving a response rate of $97.6 \%$. Of those

Table I Age and sex distribution of survey participants

\begin{tabular}{llll}
\hline & Female & Male & Total \\
\hline Age group (years) & & & \\
I5-20 & 40 & $4 \mid$ & $8 \mathrm{I}$ \\
$2 \mid-30$ & 243 & 157 & 400 \\
$3 \mid-40$ & 2 & 4 & 6 \\
Not stated & $\mathrm{I}$ & - & $\mathrm{I}$ \\
Total & 286 & 202 & 488 \\
\hline
\end{tabular}


Table 2 Knowledge of timeframe for the use of emergency contraceptives

\begin{tabular}{llll}
\hline & Female & Male & Total \\
\hline Morning after & 14 & 8 & 22 \\
Within 24 hours & 90 & 70 & 160 \\
Within 48 hours & 16 & 18 & 34 \\
Within 72 hours & 26 & 2 & 28 \\
Longer than 72 hours & 50 & 31 & 81 \\
Don't know & 60 & 50 & 110 \\
Don't know what EC is & 14 & 7 & 21 \\
Total & 270 & 186 & 456 \\
\hline
\end{tabular}

who responded, 286 (58.6\%) were female and $202(41.4 \%)$ were male, and $400(82.0 \%)$ were between 21 and 30 years of age (see Table 1). One hundred and eight (22.1\%) had used emergency contraceptive pills or given it to a partner before, whereas three hundred and eighty (77.9\%) had never used it or given it to a partner before.

Table 2 shows the participants' knowledge of the timeframe in which EC should be used. Two hundred students $(45.9 \%)$ knew the timeframe to use EC, while $110(24.1 \%)$ were not aware. Twenty-one participants $(4.6 \%)$ were unaware of the existence of EC. Thirty-two participants did not respond to this question.

Participants were asked whether they were aware of the availability of EC without a prescription, in a pharmacy. Two hundred and eighty two (57.8\%) were aware of this, while 201 (41.2\%) were not aware. Five participants did not respond to the question.

One hundred participants (20.7\%) knew the cost of EC, while $236(48.6 \%)$ believed that it was more expensive than it actually is. One hundred and twenty-four $(25.7 \%)$ believed that EC was free, and $28(5.8 \%)$ did not know the cost. There was no response from five participants (see Table 3).

Table 4 shows the comparison between male and female readiness to purchase EC in a pharmacy where they are well-known. One hundred and fifty participants (32.9\%) reported that they would feel too embarrassed to purchase the pills, while $164(36.0 \%)$ said that they would feel a bit embarrassed, and 152 (33.4\%) said that they would not

Table 3 Participants' understanding of the cost of emergency contraceptives

\begin{tabular}{llll}
\hline & Female & Male & Total \\
\hline$<$ US\$1.3 & 57 & 43 & 100 \\
$>$ US\$1.3 & 140 & 96 & 236 \\
Free & 69 & 50 & 119 \\
Don't know & 20 & 8 & 28 \\
Total & 286 & 197 & 483 \\
\hline
\end{tabular}

Table 4 Perceived ability to purchase emergency contraceptive in a pharmacy where one is known

\begin{tabular}{llll}
\hline & Female & Male & Total \\
\hline Too embarrassed & 100 & 50 & 150 \\
Bit embarrassed & 84 & 80 & 164 \\
Not embarrassed & 85 & 56 & 141 \\
Total & 269 & 186 & 455 \\
\hline
\end{tabular}

be embarrassed at all. The remaining participants did not respond to this question.

\section{Discussion}

The majority of students included in this survey were in the age group of 21-30 years, the demographic most at risk of unintended pregnancy following unprotected intercourse. ${ }^{15}$ Individuals in this group may have multiple sexual partners and may not always use contraceptives, and many would be expected to be sexually active - various studies carried out in Nigeria indicate that young people often first have sexual intercourse at between 12 and 20 years, with a mean of $16 \pm 1.2$ years. ${ }^{12,16}$

A relatively low percentage of participants had used emergency contraceptive pills, although many were aware of availability. This finding is similar to that of other studies in Nigeria, ${ }^{16}$ Ghana, ${ }^{17}$ and South Africa, ${ }^{18}$ and could be due to a fear of side effects, objections from their partner, conflicts with religious beliefs, and the belief that it can lead to permanent infertility, all of which were cited in previous studies carried out in Nigeria. ${ }^{19,20}$ Despite the high maternal mortality rate attributable to complications of induced abortion, there are very few programs designed to increase awareness of EC. ${ }^{21}$ A study in Nigeria revealed that all respondents who had terminated a pregnancy indicated that they would have used EC had they known about it. ${ }^{16}$ In addition, sexual and reproductive health education is not part of the curriculum in primary and secondary schools in Nigeria.

The extent to which participants would be embarrassed buying EC in a pharmacy where they are known is of major relevance to the availability of EC in rural areas, a result which is similar to a study performed in Australia. ${ }^{22}$ Since there are no medical contraindications to EC, purchase can be made easier - for example, by discretely but clearly displaying EC for the customer to purchase, as is done with condoms.

\section{Conclusion}

There was a lack of knowledge regarding the availability and cost of EC among students in tertiary institution in the rural community in Nigeria. The results of this survey suggest the 
need for a campaign to promote awareness of EC within the general community, especially in rural areas. Any campaign should also include information about the desirability of ongoing contraception and safe sexual practices. There is also the need to include reproductive health in the school curriculum.

\section{Disclosure}

The authors declare no conflict of interests.

\section{References}

1. Jamieson MA, Hertweck SP, Sanfilippo JS. Emergency contraception: lack of awareness among patients presenting for pregnancy termination. J Pediatr Adolesc Gynecol. 1999;12(1):11-15.

2. International Consortium for Emergency Contraception: Emergency contraceptive pills. Washington DC. 2nd edition. 2004.

3. Trussel J, Ellertson AC, Rodriguez G. The Yuzpe regimen of emergency contraception: how long after the morning after? Obstet Gynecol. 1996;88(1):150-154.

4. Fine P, Mathe H, Gindé S, Cullins V, Morfesis J, Gainer E. Ulipristal acetate taken 48-120 hours after intercourse for emergency contraception. Obstet Gynecol. 2010;115(2 Pt 1):257-263.

5. Piaggio G, Kapp N, von Hertzen $H$. Effect on pregnancy rates of the delay in the administration of levonorgestrel for emergency contraception: a combined analysis of four WHO trials. Contraception. 2011;84(1):35-39.

6. Monjok E, Smesny A, Ekabua JE, Essien EJ. Contraceptive practices in Nigeria: Literature review and recommendation for future policy decisions. Open Access Journal of Contraception. 2010;1:9-22.

7. National Population Commission (Nigeria), Macro International, Inc. Nigeria Demographic and Health Survey 1999. Calverton, United States: Macro International, Inc.

8. Adinma BD. An overview of the global policy census on women's sexual and reproductive rights: The Nigerian perspective. Trop Journal Obstet Gynaecol. 2002;19:9-12.
9. Ako SN, Etek N, Tonye R, Mbu R, Leke RJ. Induced abortion and maternal mortality: the case of central maternity hospital Yaounde. Canadian Journal of Medicine. 2003;12:21.

10. Mirembe FM. A situation analysis of induced abortions in Uganda. Afr J Fertil Sexual Reprod Heal. 1996;1(1):79-80.

11. Prine L. Emergency contraception, myths and facts. Obstet Gynecol Clin North Am. 2007;34(1):127-136.

12. Oye-Adeniran BA, Adewole IF, Odeyemi KA, Ekanem K, Umoh AV. Contraceptive prevalence among young women in Nigeria. $J$ Obstet Gynaecol. 2005;25(2):182-185.

13. Cohen J. Statistical Power Analysis for Behavioral Sciences. 2nd ed. Hillsdale, NJ: Routledge Academic; 1988.

14. Lemeshow S, Hosmer DW, Klar J, Lwanga SK. Adequacy of Sample Size in Health Studies. New York, NY: John Wiley \& Sons; 1990.

15. Population Information Programme: centre for communication programs (1995). Meeting the needs of young adults. Population Reports Series 1 no 4,p6.

16. Arowojolu AO, Adekunle AO. Perception and practice of emergency contraception by post-secondary school students in southwest Nigeria. Afr J Reprod Health. 2000;4(1):56-65.

17. Baiden F, Awini E, Clerk C. Perception of university students in Ghana about emergency contraception. Contraception. 2002;66(1):23-26.

18. Roberts C, Moodley J, Esterrhuizen T. Emergency contraception: knowledge and practices of tertiary students in Durban, South Africa. J Obstet Gynaecol. 2004;24(4):441-445.

19. Okpani AOU, Okpani JU. Sexual activity and contraceptive use among female adolescents - a report from Port Harcourt, Nigeria. Afr J Reprod Health. 2000;4(1):40-47.

20. Abiodun OM, Balogun OR. Sexual activity and contraceptive use among young female students of tertiary educational institution in Ilorin, Nigeria. Contraception. 2009;79(2):146-149.

21. Ellertson C, Shocket T, Blanchard K, Trussell J. Emergency contraception; a review of the programmatic and social science literature. Contraception. 2000;61(3):145-186.

22. Mohoric-Stare D, De Costa C. Knowledge of emergency contraception amongst tertiary students in far North Queensland. Australian N Z J Obstet Gynaecol. 2009;49(3):307-311.
Open Access Journal of Contraception

\section{Publish your work in this journal}

Open Access Journal of Contraception is an international, peerreviewed, open access, online journal, publishing original research, reports, reviews and commentaries on all areas of contraception. In addition to clinical research, demographics and health-related aspects, the journal welcomes new findings in animal and preclinical studies

\section{Dovepress}

relating to understanding the biological mechanisms and practical development of new contraceptive agents. The manuscript management system is completely online and includes a very quick and fair peer-review system. Visit http://www.dovepress.com/testimonials.php to read real quotes from published authors. 